This is the peer reviewed version of the following article: Eades C, France E \& Evans J (2018) Postnatal experiences, knowledge and perceptions of women with gestational diabetes, Diabetic Medicine, 35 (4), pp. 519-529, which has been published in final form at https://doi.org/10.1111/dme.13580. This article may be used for non-commercial purposes in accordance With Wiley Terms and Conditions for self-archiving. 


\section{Postnatal experiences, knowledge and perceptions of women with gestational diabetes.}

Claire E Eades, Faculty of Health Sciences and Sport, University of Stirling

Emma F France, Faculty of Health Sciences and Sport, University of Stirling

Josie MM Evans, Faculty of Health Sciences and Sport, University of Stirling

Correspondence to:

Josie Evans

Faculty of Health Sciences and Sport

University of Stirling

Stirling

FK9 4LA

Josie.evans@stir.ac.uk

Tel: +44 (0) 1786466342

Fax: +44 (0) 1786466333

Abstract word count: 250

Manuscript word count: 5,109 (including quotes) 4,000 (excluding quotes)

Running title: Women's experiences of gestational diabetes

Conflict of Interest Disclosures: None

\section{Novelty Statement}

This qualitative study exploring the experiences of 16 women with gestational diabetes has established the following:

- That gestational diabetes is not seen as an important, or even real diagnosis, among some women.

- That this perception may come about as a result of perceived minimal impact of gestational diabetes on women's lives

- That this perception may be re-inforced by a lack of aftercare once gestational diabetes resolves post-pregnancy

- Educational interventions are needed to address illness perceptions surrounding gestational diabetes, while lifestyle interventions could use the child's health as a motivator for joint or family interventions. 


\section{Abstract}

Introduction: Women with gestational diabetes mellitus (GDM) are at increased risk of Type 2 diabetes (T2DM). This study aimed to explore experiences, knowledge and perceptions of women with GDM to inform the design of interventions to prevent or delay T2DM. Methods: Semi-structured interviews were carried out with 16 women with GDM who were recruited from a clinic in one Scottish health board. Framework approach was used to manage and analyse data according to themes informed by psychological theory (Self Regulation Model and Theory of Planned Behaviour). Results: GDM is not seen as an important, or even real diagnosis, among some women, and this perception may result from perceived minimal impact of GDM on their lives. Some women did experience a bigger emotional and practical impact. Knowledge and understanding of T2DM was poor in general and many women were unconcerned about their future risk. Lower concern appeared to be linked to lower perceived impact of GDM. Lifestyle changes discussed by women mostly related to diet and were motivated primarily by concern for their baby's health. Many women did not maintain these changes postnatally, reporting significant barriers. Conclusions: This study has suggested potential avenues to be explored in terms of content, timing and potential recipients of interventions. Educational interventions postnatally could address illness perceptions in women with GDM and redress the situation where lack of aftercare downplays its seriousness. For lifestyle interventions, the child's health could be used as a motivator within the context of a joint or family intervention later on. 


\section{Introduction}

Women with gestational diabetes mellitus (GDM) are at a particularly increased risk of developing Type 2 diabetes (T2D). GDM affects around $5 \%$ of pregnancies in Europe ${ }^{1}$. In women with GDM, normal glucose regulation usually returns shortly after delivery but these women have up to a seven-fold increased risk of T2D compared to women who have not had $\mathrm{GDM}^{2}$. Lifestyle interventions targeted at high risk individuals can prevent or delay the onset of $\mathrm{T}_{2} \mathrm{D}^{3}$. However, the evidence for interventions that specifically target women with prior GDM is not as compelling ${ }^{4}$ and many studies report difficulties in recruiting and retaining participants $^{5}$. The challenges facing women with GDM in making lifestyle changes are potentially quite different to those facing other high risk patient groups (eg people with impaired glucose regulation). Learning about the experiences of women with GDM may help to identify whether and which common beliefs and perceptions might be a barrier (or facilitator) to behaviour change, and to help ensure that interventions are appropriately tailored to them. This is important because uptake and engagement with such interventions can be compromised if insufficient attention is paid to the values and concerns of the intended recipients.

There has been relatively little research in the UK exploring the perceptions of women with GDM about this condition and their future risk of T2D. Although there has been a metasynthesis of 16 studies on this topic ${ }^{6}$, only one study is UK-based ${ }^{7}$. The studies have shown that some women have awareness of their increased T2DM risk, but lifestyle changes that are made during pregnancy are difficult to maintain in the longer-term ${ }^{7}$. Clearer information is needed, and interventions required that are tailored to women as patients, but also as caregivers ${ }^{6}$.

The Medical Research Council (MRC) guidance on developing complex interventions suggests that an appropriate theoretical basis should be identified at the earliest stages of intervention development ${ }^{8}$. It is argued that the use of theory in intervention design increases the likelihood that an intervention will be effective by ensuring that the causal determinants of behaviour are understood and addressed ${ }^{9}$. The overall aim of this study was therefore to explore qualitatively the perceptions and experiences of women with GDM in Scotland surrounding their diagnosis, their future risk of T2D and preventative lifestyle behaviour, and to identify implications for the development of potential interventions to reduce subsequent T2DM risk. 


\section{Methods}

\section{Theoretical Framework}

This study was framed by a theoretical approach which combined both the Self Regulation Model $^{10}$ and the Theory of Planned Behaviour ${ }^{11}$. The Self Regulation Model ${ }^{10}$ focuses on patients' beliefs about their health condition and proposes that people interpret information about a potential illness to create a 'lay' view or representation of the illness. The coping responses then employed (e.g. adhering to treatment regimens or attending appointments), are related to the illness representations the individual holds and to their appraisal of how successful they perceive chosen coping responses to be. These illness representations are formed around seven different themes: identity (label or diagnosis of illness), cause (factors believed to have caused the illness), timeline (expected duration of illness), consequences (expected effects of illness on physical, social and psychological well-being), control/cure (extent to which illness can be controlled/cured), emotional representations (emotional responses to an illness) and illness coherence (how well the person understands their illness).

The Theory of Planned Behaviour ${ }^{11}$ is concerned with beliefs about lifestyle behaviours and asserts that voluntary behaviours are largely predicted by our intentions regarding the behaviour. Intentions in turn are determined by our attitude towards the behaviour (our judgement of whether the behaviour is a good thing to do), subjective norms (our judgement of what important others think of the behaviour), and perceived behavioural control (our expectation of how successful we will be in carrying out the behaviour).

These psychological models have been widely used to understand a wide range of health behaviours and because there was no clear evidence to suggest which approach might be most appropriate in the context of the questions posed by our study ${ }^{12,13}$, both models were used to underpin our theoretical approach.

\section{Participants and recruitment}

Women were recruited from a diabetes antenatal clinic operating in a single Health Board in Scotland, UK. They were eligible if they were aged 18 years and over, spoke fluent English and had been diagnosed in their current pregnancy with GDM according to the Scottish Intercollegiate Guidelines Network guidance ${ }^{14}$. Clinical staff identified eligible 49 women 
from hospital records, gave them information about the study at the clinic and then asked if they were willing for the researcher (CE) to receive their contact details; all women agreed. A convenience sampling approach was used ${ }^{15}$. Interested women either gave their details directly to $\mathrm{CE}$ (if she was present) or details were given to $\mathrm{CE}$ via clinical staff. The women then received an information sheet about the study and informed that they would potentially be contacted from 8 weeks after delivery. The plan was to conduct approximately 20 interviews, so not all women would be interviewed, and CE collected more names than necessary to allow for drop out. During a post-delivery telephone call, CE checked if the woman was still willing to participate, then scheduled an interview. She had therefore either met or spoken by telephone to every participant before data collection. The final sample size was determined by data saturation, whereby CE conducted interviews until it was felt that no new ideas were being offered by participants.

\section{Data collection}

Attempts were made to contact 31 of 49 women post-delivery; women were selected in order to achieve maximum variation in factors such as age, parity, ethnicity and body mass index. Thirteen women could not be reached using the telephone number held by the researcher and two stated they no longer wished to take part. The remaining 16 women were interviewed between January 2015 and August 2017 (Table 1). All interviews were conducted within a year of the women's due date; the majority (14) between 12 and 26 weeks afterwards. Interviews took place in participants' homes and were carried out by $\mathrm{CE}$ (then a part-time $\mathrm{PhD}$ student and a registered health psychologist) with previous experience of qualitative fieldwork. The only other individuals present were the baby, or occasionally other children. Participants knew that CE was conducting the study as part of her research degree and that she was not a member of clinical staff but was simply interested in finding out their thoughts on the topic. They were also told that there were no right or wrong answers.

The semi-structured format following an interview guide informed by underlying theory, ensured that the topics of interest were covered while allowing interviewees the freedom to discuss any issues not covered in the guide. The main topics covered were experiences of diagnosis of GDM; feelings about GDM diagnosis; consequences of GDM; understanding of GDM and information given by healthcare staff; understanding of T2DM and information given by healthcare staff. Only if it was clear that the participant was already aware of increased risk of T2DM, were the following topics also discussed: understanding of T2DM 
prevention; lifestyle changes for T2DM prevention; advantages and disadvantages of making lifestyle changes for T2DM prevention; views on receiving support to make lifestyle changes after having GDM.

Interviews were audio-recorded with the participant's permission and transcribed verbatim by a professional transcription service (but not returned to the participants). Interviews lasted between 11 and 66 minutes, and field notes written up afterwards. Written informed consent was obtained from all participants and approval to conduct the study was obtained from a National Health Service (NHS) Research Ethics Committee.

\section{Data Analysis}

Fieldwork and analysis were conducted in parallel rather than sequentially. The framework method $^{16}$ was used to organise and analyse the data combined with coding in NVivo 11 qualitative data analysis software. The framework method is relatively structured and allows pre-set objectives and reasoning to inform data collection whilst still allowing original contributions from participants. The approach involves researchers familiarising themselves with the interview transcripts, then re-reading them and paraphrasing or labelling any passages they interpret as important. These labels can come from predefined theories or models or can be "open", that is where anything that is relevant from any perspective is labelled. In this study the three authors independently reviewed three transcripts and identified and coded areas of interest using an open approach. This open approach was used for the first few transcripts to ensure that any concepts or themes deriving from the data (as well as from theory) were identified.

The three authors then compared their open coding of the three transcripts and agreed that most of the codes could be organised under subthemes derived from the theoretical concepts of the Self Regulation Model and the Theory of Planned Behaviour. Subthemes were organised under topic themes including GDM, T2DM, diet, exercise and reactions to a proposed future GDM intervention. Subthemes included, for example, identity, cause, timeline, consequences, and control (for data about GDM and T2DM). Additional dataderived subthemes included, for example, education about GDM and risk perceptions related to T2DM. The full list of themes and subthemes are shown in Table 2.

CE then applied the analytical framework to the remaining transcripts and data were summarised using matrices ${ }^{17}$. Six separate matrices were created, one for each topic theme. 
Each column was labelled with a subtheme (except column one which contained a participant identifier and demographic data). Each row represented one participant. In each cell of the matrix, relevant data were summarised and a supporting quote given (a matrix excerpt is shown in Appendix 1). A further summary matrix was used to juxtapose each summary of the participants' understanding, and perceived impacts, of GDM and T2DM. Abstraction and interpretation followed; the matrices were read repeatedly to identify common patterns and disconfirming cases using constant comparison. The findings are presented below as overarching key themes (as depicted in Fig 1). 


\section{Results}

The results are discussed under the following overarching themes (mapping to key themes two to six): (1) understanding of GDM; (2) impact of GDM; (3) understanding of T2DM and future risk; (4) lifestyle change during and after pregnancy; (5) prevention of T2DM. Verbatim quotes from study participants are identified by participant number. Table 1 provides their characteristics.

\section{(1) Understanding of GDM}

Most women felt they had a good understanding of GDM during their pregnancy. With the time that had elapsed since being diagnosed they struggled to recall specific information about the condition, but most held an overall impression that the information they were given by NHS staff was clear and at an appropriate level. Many praised the staff involved in their care.

"Erm, and they were very good, [the Health Board] were really, really good. I mean it was, it was about an hour and a half, two hours with the diabetic nurse and she went through everything of... and how to use the machine and everything as well." (P9)

When women were less satisfied with the information that they were given, it was generally because this was too vague and not tailored to their specific circumstances, producing feelings of frustration.

"Really to, obviously to eat healthily and exercise but I think the problem is it's very vague as to what eating healthily is. " (P7)

"Nobody actually sat down with me and tell me, here's the list of all the food. They gave me a couple of leaflets, erm, but you know, the leaflets is for, erm, you need to customise them based on the patient, what type of food they're used. Because if you're, if you keep telling them, oh don't take, don't have a takeaway, well, I don't have a takeaway, I've already been having healthy eating." (P15)

Although most women explicitly stated that they felt they understood GDM, further discussion revealed areas of confusion or misconception. One was related to the diagnosis of GDM, with some women questioning whether they ever really had the condition. Some suspected that high blood glucose readings identified during diagnostic testing were caused 
solely by food they had eaten recently, and others felt that a diagnosis very late in pregnancy or one that was classed as borderline meant that the diagnosis was less relevant to them.

"I actually had a big bar of chocolate the day before I went, so I was thinking I bet it's just cause of that." (P8)

"most of what they were telling you wasn't going to really apply to me because I only had, erm, a couple of weeks to go before, erm, I reached my term time." (P6)

These women often rationalised that since they met the diagnostic criteria for GDM they must have had GDM, but still found themselves questioning the diagnosis.

"So, in one sense you kind of think to yourself, maybe I didnae have it all, and it was just... well obviously I did because I had the fasting thing beforehand" (P1)

Although not explicitly stated by participants, this questioning of the diagnosis was possibly linked to their perception that GDM had little impact on their lives; many women who questioned their diagnosis did not experience any symptoms, found GDM easy to control through diet, and had blood glucose readings in the normal range during pregnancy and when tested postnatally.

Other common misconceptions related to the causes of GDM. Although some women correctly identified being overweight, family history of T2DM and ethnicity as risk factors for developing GDM, eating sweet and sugary foods was more commonly understood to have been the cause of this condition.

"I was a sugar person first, yeah, yeah, I liked sugar very much... I said to the person, maybe because I eat sugar too much." (P10).

\section{(2) Impact of GDM}

Perceptions of how much GDM impacted upon participants' lives varied. We identified three groups of women: women for whom the diagnosis had little emotional impact; those for whom the impact was related to concerns about the wellbeing of their unborn baby; and those for whom the negative emotional impact appeared to last beyond pregnancy. However, the three groups are not necessarily exhaustive or mutually exclusive; this is an emergent finding that needs to be verified. 
Women in the first group reported that they were not worried or concerned by the condition at all, with this lack of concern often related to the fact that the condition was relatively common and had little impact on their day to day life.

"it was quite common, so...that sort of puts your mind at ease, it didn't scare me or anything. So, it was okay. Knowing that lots of people get it and it was quite normal..." (P2)

"but if you manage it quite well it's nothing for you, it's like a part of brushing teeth every day, it's like that. You don't even feel like bad that you've got that gestational diabetes; I never felt bad." (P5).

These women explained that the only real consequence of their diagnosis was having to make changes to their diet, which were viewed as being easy to make, and simply involving cutting out or cutting down sugary foods and drinks; the condition was something temporary that they could forget about after they gave birth.

"No, it's just like a, erm, like buying maternity clothes, and gestational diabetes is like that, and you just forget everything" (P5).

A second group of women had a strong emotional response to being diagnosed with GDM. This was usually caused by worry and guilt that they might have put their unborn baby's health at risk.

"I did, I felt...I actually had a wee cry. I was like, oh, I just felt like I'd let myself down and...maybe I just pigged out [over ate] too much. Um, and just felt as if I'd let her down." (P8)

Often this concern eased after the initial diagnosis as the women learned more about the condition and found that they were able to control and manage it.

"Um, no, to be honest with you, when, when, when I kept checking my sugar levels and that, I just, kind of, thought, well, cannae be that much of a big thing because I'm, I'm not over and I'm not under." (P8)

Less commonly, concern and emotion about being diagnosed with GDM did not lessen over time, and women in the third group reflected that they were still affected by their diagnosis now. These women had often had a much more difficult time in controlling the condition, 
requiring dietary control to be supplemented with insulin and medication (something which many women stated being reluctant to do). They reported it as time consuming, they found injecting unpleasant and they suffered side effects from the medication.

"So, um, I ended up having to take insulin, which was horrible as well...because they're a needle again. So then I'm testing myself three times a day and my insulin at night, oh, it was just horrible." (P16)

\section{(3) Understanding of T2DM and future risk}

General understanding of T2DM was very poor. A lack of understanding around types of diabetes and the differences between them was widespread, with many women unable to name T2DM, and knowing little about it. Some women did identify poor diet and overweight as risk factors for T2DM and knew that it is controlled through diet and/or medication; but very few mentioned the health consequences of T2DM and those who did were very vague about these.

"And obviously there's other health stuff as well at the back of it" (P1)

There were some misconceptions over the causes of T2DM and its severity. Some women who had older relatives with T2DM believed it was a consequence of older age; others downplayed its seriousness, especially when they held a preconception that T2DM had little impact.

"So, it's only type two so it's...I suppose, it's not as bad but" (P4)

"Erm, but my partner's mum she's got type two diabetes and I know that she takes a tablet. I'm sure it's in the morning. And that does her throughout the day" (P4)

Nearly all women recalled being told that they were at an increased risk of diabetes in the future as a result of having had GDM (although few understood the time frame), and that they could reduce their risk through changes to their diet and physical activity levels.

"Maybe not this early and this quick after having them...but probably more than likely later on in life, like maybe when I'm 50, 60, they said that I'll probably, I'll probably be likely to have it, yeah." (P16) 
However, many women downplayed the risk for themselves, indicating that because they were not overweight or had no other health problems, or because they had a late diagnosis during pregnancy, this meant that their risk was lower than for other women.

"I have to go every year now for blood tests because of it and I do think it's pretty pointless to be perfectly honest because I think if it hadn't been diagnosed, then they would never have been none the wiser. I don't think it's something that I need to worry about in the future to be honest." (P6)

"she has taken my three-day result, or something, and she took my blood as well on that day, and she counted. And she said ..........you're not that much, er, risk of getting Type 2 diabetes. So I thought, okay, that's fine." (P5).

The extent to which women felt concerned by their increased risk of T2DM varied, but overall concern was not high. Many women made no mention of being worried about their risk of T2DM and one group of women felt that any risk was far in the future.

"it's not an immediate thing for me, I'm not that fussed about it just now." (P9)

However, one participant had a difficult time managing her GDM when pregnant and felt that it had quite a big impact on her day to day life, as did another participant who reported being concerned about her future risk of T2DM. This suggests that concern about future risk of T2DM may be linked to more severe perceived or actual impact of GDM.

"I really would hate to be...to get diabetes again. It's horrible" (P3)

\section{(4) Lifestyle change during and after pregnancy}

Lifestyle changes discussed in the interviews predominantly related to changes to diet rather than physical activity. Women commonly described cutting out sweet foods, fizzy drinks and other junk food in response to their GDM diagnosis, after initially having been 'eating for two'.

"I say, for me it was just cutting back on eating cakes and chocolates, which is what I'd been having ... being pregnant" (P7) 
The dietary changes that women made after a GDM diagnosis were most commonly motivated by their concern for the health of their unborn baby and also by a desire to avoid taking medication to manage their GDM.

" just thought of the baby and...obviously I didn't want her to be in any danger when she was, when I was having her or anything like that, any complications or anything like that, so it had to be done." (P8)

"changed my diet just to, kind of, make sure that...because I didn't...I really didn't want to have any, kind of, medication whether it was tablet or, eh, like injection" (P4)

A few women did manage to continue with these changes postnatally, and were currently attending commercial weight loss groups, but most had not managed to maintain the changes. Once the above motivations had passed, looking after their own health postnatally was not a priority for some women, especially in the face of many new challenges.

"No, but you, you just need to find some energy sometimes. And eating seems to be the right plan for that, but it never is. You just, you know, the sleep deprivation, and, erm, the constant, kind of, needing to be someone else's...you don't really look after yourself so much." (P13)

Changes to physical activity levels were less commonly discussed by participants in this study. Some women recalled being advised to increase their activity levels when they were diagnosed (although this advice was briefer and more peripheral to the education they received on diet), while others did not receive any such advice. There was therefore confusion over what was appropriate.

"I mean exercise, like I said, do more exercise. Walking, jogging, it...what kind of, you know, what, what would prevent it? So no, they didn't really... It was just like do some more exercise and stuff, yeah." (P9)

Among those who did increase physical activity levels, walking, then swimming, were the activities most frequently mentioned. Some women who had previously been active managed to continue this activity during their pregnancy while others reported that they reduced or stopped this exercise during pregnancy. Barriers included having a bump and feeling heavily 
pregnant, pregnancy-related back and pelvic pain, the demands of having one or more children to look after, tiredness and poor weather.

"where exactly am I meant to go and how am I meant to do this, when I can't nip out to the gym, I can't go and walk the dog, or I can't nip out and see a friend 'cause she's in bed" (P1)

\section{(5) Prevention of T2DM}

The majority of women stated that they would be open to additional support to make lifestyle changes after giving birth. However, two women stated clearly that they would not be interested, while another felt that there was already support available. Among those women who welcomed the idea there was a feeling of being left on their own after the high level of care they had received when they had GDM.

"Um, yeah, I would have...probably...looking back on it now, um, I'd have maybe liked a wee bit more, like, sort of, closure on it, a wee bit more explanation” (P12)

While some women were invited to attend postnatal testing to ensure that their blood sugar levels had returned to normal, others reported that they had to arrange this testing themselves. This lack of aftercare led some women to question how serious their increased risk of T2DM was.

"But because there's nothing...no after care as such...then you know, it's not like a major thing." (P9)

These women felt that a greater level of aftercare might help to increase their motivation to make lifestyle changes to reduce their T2DM risk. Some suggested that additional blood testing over the longer term would be beneficial. One woman who was awaiting the results of her postnatal testing described how going for this test had made her think more consciously about her lifestyle.

"when I had the letter through for to say for to go, em, for to get tested, and then you start to think, aah, oh wait a wee minute... and then have I really been paying attention or have I not ...I know this sounds terrible, but in one sense I'm hoping it comes back quite high to give myself sort of a kick in the bum, do you know what I mean." (P1)

As previously discussed, some women felt a need for more specific information about making changes to their lifestyle and suggested that this could be tied in with going for 
postnatal blood testing. Other women felt that group support to make lifestyle changes that involved other mums would be most beneficial for them.

“As much as I love my mum, not just your mum going...you're doing well and you've lost a wee bit of weight, well done and it took me so long after I'd had babies and stuff, but girls that are going through it...that are exactly the same as you. And that's been a really good support network...” (P2)

Women who lived outwith the main towns/cities in the health board also noted that there were fewer group activities available to them. 


\section{Discussion}

This study provides an understanding of women's perceptions and experiences of GDM, of making lifestyle changes after a diagnosis of GDM and their risk perceptions about T2DM. In general, most women in this Scottish study had a positive experience of health care after their GDM diagnosis, as reported elsewhere in the $\mathrm{UK}^{7}$, but in contrast to the findings from a synthesis of international qualitative studies ${ }^{6}$. However, women identified an explicit need for more specific dietary advice, and advice on physical activity, during pregnancy and in the postnatal period.

While the transitory nature of GDM was emphasised by some women in this, and other studies $^{6}$, the belief that GDM is not an important (or even real) diagnosis, has not previously been explored, and often occurred among women for whom the perceived impact of GDM was minimal. Similarly, while most women had some (often vague) awareness of their future T2DM risk (confirming previous studies ${ }^{6,7}$ ), a lack of concern appeared to tie in again with a minimal perceived impact of GDM. This is an important group of women to identify and target for preventative intervention, so that they understand the importance of behaviour change even if their GDM diagnosis did not seem significant at the time.

The perception among some women that GDM was an insignificant diagnosis without longerterm implications, was reinforced by the perceived lack of after care and follow-up. If such follow-up were provided, this might act to counter the postnatal resolution of GDM 'lulling women into complacency ${ }^{7}$.

Many women did achieve dietary and/or exercise behaviour change during pregnancy, and this was often motivated primarily by concern for their baby's health. This ties in with the worry and guilt that increased the emotional impact of GDM among some women. However, awareness of $\mathrm{T} 2 \mathrm{DM}$ risk did not provide sufficient motivation to overcome barriers to lifestyle change postnatally (including tiredness, lack of energy and the demands of a new baby).

The strengths of this study include the participation of women with a range of different demographic characteristics such as age, ethnicity, and deprivation. By using theoretical models to inform the design and analysis, we have highlighted a range of beliefs and illness perceptions which impact upon lifestyle change both during and after pregnancy. The sample size was relatively small and all women were recruited from one health board; this may mean 
that the experiences of care that women reported may not be comparable to women in other geographical areas. It was also only possible to ask questions about women's views surrounding T2DM once they had indicated that they were already aware of their increased T2DM risk. While this may have introduced a slight bias, it was a requirement stipulated for ethical reasons, in order that women were not distressed by their sudden realisation of longerterm and more serious consequences of GDM. While we ensured that a selection of transcripts were coded independently by all three authors and the framework was developed through discussion between them to allow for varied and richer interpretations of the data, it is still possible that this study was influenced by the researchers' backgrounds and beliefs. Despite these limitations, our findings accord and build upon those from a previous UK study ${ }^{7}$.

Findings for this study have important implications for the development of potential interventions for women who have had GDM. Regarding educational interventions, given the perception of GDM as being short-lived, easily controlled and having few consequences, this study suggests that illness perceptions surrounding GDM (as defined in the Self Regulation model), particularly the 'consequences', need to be addressed; and would be appropriately aimed at women for whom the perceived impact of GDM was minimal. The 'timeline' and 'consequences' of T2DM are also poorly understood and could be tackled. Timing such an educational intervention soon after delivery, combined with longer-term follow-up and testing, would help to redress the situation where a current lack of aftercare downplays the seriousness of GDM and subsequent T2D risk.

In terms of lifestyle interventions for behaviour change, it is clear that women feel the need for more specific dietary and physical activity advice. There are significant barriers to behaviour change with a young family (perceived behavioural control in the Theory of Planned Behaviour). However, given that the health of their unborn baby facilitates behaviour change during pregnancy, it may be that an important source of motivation later on could be their child's health, which could be used in order to target behavioural attitudes and intentions within the context of a joint or family intervention. While other studies have identified weaning as a time of increased receptiveness to lifestyle change ${ }^{6}$, this logic could extend to other times during a child's development.

In summary, this qualitative research with women about their experiences of GDM, underpinned by psychological theory, has suggested potential avenues to be explored further 
in terms of content, timing and potential recipients of interventions to reduce the risk of T2DM in women who have had GDM. 


\section{References}

1. Eades, C., Cameron, D. \& Evans, J.M.M. (2016) Prevalence of gestational diabetes: a meta-analysis. Diabetes Research and Clinical Practice, 139, 173-181.

2. Bellamy, L., Casas, J., Hingorani, A.D., Williams, D. (2009) Type 2 diabetes mellitus after gestational diabetes: a systematic review and meta-analysis. The Lancet, 373 (9677), 1773-1779.

3. Gillies, C.L., Abrams, K.R., Lambert, P.C., Cooper, N.J., Sutton, A.J., Ron T Hsu, et al. (2007). Pharmacological and lifestyle interventions to prevent or delay type 2 diabetes in people with impaired glucose tolerance: systematic review and metaanalysis. British Medical Journal, 334 (7588), 299.

4. Gilinsky, A.S., Kirk, A.F., Hughes, A.R., \& Lindsay, R.S. (2015). Lifestyle interventions for type 2 diabetes prevention in women with prior gestational diabetes: A systematic review and meta-analysis of behavioural, anthropometric and metabolic outcomes. Preventative Medicine Reports, 2, 448-461.

5. Cheung, N.W., Smith, B.J., van der Ploeg, H.P., Cinnadaio, N. \& Bauman, A. (2011). A pilot structured behavioural intervention trial to increase physical activity among women with recent gestational diabetes. Diabetes Research and Clinical Practice, 92, e27-229.

6. Parsons, J., Ismail, K., Amiel, S., \& Forbes, A. (2014). Perceptions among women with gestational diabetes. Qualitative Health Research, 1-11.

7. Lie, M.L.S., Hayes, L., Lewis-Barned, N.J., May, C., White, M., \& Bell, R. (2013). Preventing Type 2 diabetes after gestational diabetes: women's experiences and implications for diabetes prevention interventions. Diabetic Medicine, 30, 986-993

8. Medical Research Council (2006). Developing and evaluation complex interventions: new guidance. (n.p.): Medical Research Council.

9. Michie, S., Johnston, M., Francis, J., Hardeman, W., \& Eccles, M. (2008). From theory to intervention: mapping theoretically derived behavioural determinants to behaviour change techniques. Applied Psychology, 57 (4), 660-680. 
10. Leventhal, H., Diefenbach, M., \& Leventhal, E.A. (1995). Illness cognitions: Using common sense to understand treatment adherence and affect cognition interactions. Cognitive Therapy and Research, 16, 143-163.

11. Ajzen, I. (1991). The theory of planned behaviour. Organizational Behavior and Human Decision Processes, 50, 179.

12. Armitage, C.J., \& Conner, M. (2001). Efficacy of the Theory of Planned Behaviour: A meta-analytic review. British Journal of Social Psychology, 40 (4), 471-499.

13. Hagger, M.S., \& Orbell, S. (2003). A meta-analytic review of the Common-Sense Model of Illness Representations. Psychology and Health, 18 (2), 141-184.

14. Scottish Intercollegiate Guidance Network (2014). Management of diabetes. A national clinical guideline. Edinburgh: Scottish Intercollegiate Guidance Network.

15. Coyne, I.T. (1997). Sampling in qualitative research. Purposeful and theoretical sampling; merging or clear boundaries? Journal of Advanced Nursing, 26 (3), 623630.

16. Spencer, L., Ritchie, J., O'Connor, W., Morrell, G. \& Ormston, R. (2014). Analysis in practice. In Ritchie, J., Lewis, J., McNaughton Nicholls, C. \& Ormston, R. (Eds.), Qualitative research practice (295-345). London: SAGE.

17. Gale, N.K., Heath, G., Cameron, E., Rashid, S. \& Redwood, S. (2013). Using the framework method for the analysis of qualitative data in multi-disciplinary health research. BMC Medical Research Methodology, 13, 117. 
TABLES

\begin{tabular}{|c|c|}
\hline Age & Number \\
\hline $20-29$ & 3 \\
\hline $30-39$ & 11 \\
\hline$>40$ & 2 \\
\hline \multicolumn{2}{|l|}{ Parity } \\
\hline+1 & 9 \\
\hline+2 & 5 \\
\hline+3 & 2 \\
\hline \multicolumn{2}{|c|}{ Gestation at diagnosis of GDM } \\
\hline $1^{\text {st }}$ trimester & 2 \\
\hline $2^{\text {nd }}$ trimester & 5 \\
\hline $3^{\text {rd }}$ trimester & 8 \\
\hline \multicolumn{2}{|c|}{ SIMD Deprivation Category } \\
\hline 1 (most deprived) & 2 \\
\hline 2 & 2 \\
\hline 3 & 5 \\
\hline 4 & 3 \\
\hline 5 (least deprived) & 4 \\
\hline \multicolumn{2}{|l|}{ Ethnicity } \\
\hline White & 12 \\
\hline Asian & 3 \\
\hline Black African & 1 \\
\hline \multicolumn{2}{|c|}{ Key to Participants Quoted in text } \\
\hline P1 & age 39, not first child, white, middle deprivation \\
\hline $\mathrm{P} 2$ & age 42 , first child, white, low deprivation \\
\hline $\mathrm{P} 3$ & age 39 , not first child, white, high deprivation \\
\hline $\mathrm{P} 4$ & age 22, first child, white, high deprivation \\
\hline $\mathrm{P} 5$ & age 34 , first child, not white, high deprivation \\
\hline P6 & age 35 , not first child, white, middle deprivation \\
\hline P7 & age 35, not first child, white, low deprivation \\
\hline $\mathrm{P} 8$ & age 28 , first child, white, low deprivation \\
\hline P9 & age 38 , first child, not white, low deprivation \\
\hline $\mathrm{P} 10$ & age 33 , not first child, not white, middle deprivation \\
\hline $\mathrm{P} 12$ & age 38 , first child, white, low deprivation \\
\hline $\mathrm{P} 13$ & age 45 , first child, white, low deprivation \\
\hline P14 & age 32 , first child, white, middle deprivation \\
\hline P15 & age 38 , first child, not white, low deprivation \\
\hline P16 & age 25 , not first child, white, middle deprivation \\
\hline
\end{tabular}

Table 1: Characteristics of participants 


\begin{tabular}{|c|c|}
\hline Theme & Subtheme (theory subtheme relates to) \\
\hline 1. Background & $\begin{array}{l}\text { 1.1 Family history } \\
\text { 1.2 Pregnancy experience } \\
\text { 1.3 Previous GDM } \\
\text { 1.4 Postnatal testing }\end{array}$ \\
\hline 2. Gestational Diabetes Mellitus & $\begin{array}{l}\text { 2.1 Identity }\left(\mathrm{SRM}^{\mathrm{l}}\right) \\
\text { 2.2 Timeline (SRM) } \\
\text { 2.3 Cause (SRM) } \\
\text { 2.4 Consequences (SRM) } \\
\text { 2.5 Control (SRM) } \\
\text { 2.6 Emotional Representations (SRM) } \\
\text { 2.7 Illness Coherence (SRM) } \\
\text { 2.8 Education about gestational diabetes }{ }^{3}\end{array}$ \\
\hline 3. Type 2 Diabetes & $\begin{array}{l}\text { 3.1 Identity (SRM) } \\
\text { 3.2 Timeline (SRM) } \\
\text { 3.3 Cause (SRM) } \\
\text { 3.4 Consequences (SRM) } \\
\text { 3.5 Control (SRM) } \\
\text { 3.6 Emotional Representations (SRM) } \\
\text { 3.7 Illness coherence (SRM) } \\
\text { 3.8 Risk perceptions } \\
\text { 3.9 Prevention }\end{array}$ \\
\hline 4. Diet & $\begin{array}{l}\text { 4.1 Attitude }\left(\mathrm{TPB}^{2}\right) \\
\text { 4.2 Subjective Norm (TPB) } \\
\text { 4.3 Perceived Behavioural Control (TPB) } \\
\text { 4.4 Intention (TPB) } \\
\text { 4.5 Behaviour (TPB) }\end{array}$ \\
\hline 5. Exercise & $\begin{array}{l}\text { 5.1 Attitude (TPB) } \\
\text { 5.2 Subjective Norm (TPB) } \\
\text { 5.3 Perceived Behavioural Control (TPB) } \\
\text { 5.4 Intention (TPB) } \\
\text { 5.5 Behaviour (TPB) }\end{array}$ \\
\hline 6. Intervention & $\begin{array}{l}\text { 6.1 Acceptability } \\
6.2 \text { Ideas }^{3}\end{array}$ \\
\hline \multicolumn{2}{|c|}{$\begin{array}{l}{ }^{1} \text { Directly taken from illness representations of the Self Regulation Model (SRM) } \\
{ }^{2} \text { Directly taken /mapped to concepts of the Theory of Planned Behaviour (TPB) } \\
{ }^{3} \text { Data-derived subthemes }\end{array}$} \\
\hline
\end{tabular}

Table 2: Framework used to organise data 


\section{FIGURE LEGEND}

Fig 1: Which theoretical concepts informed overarching themes

\section{Overarching themes}

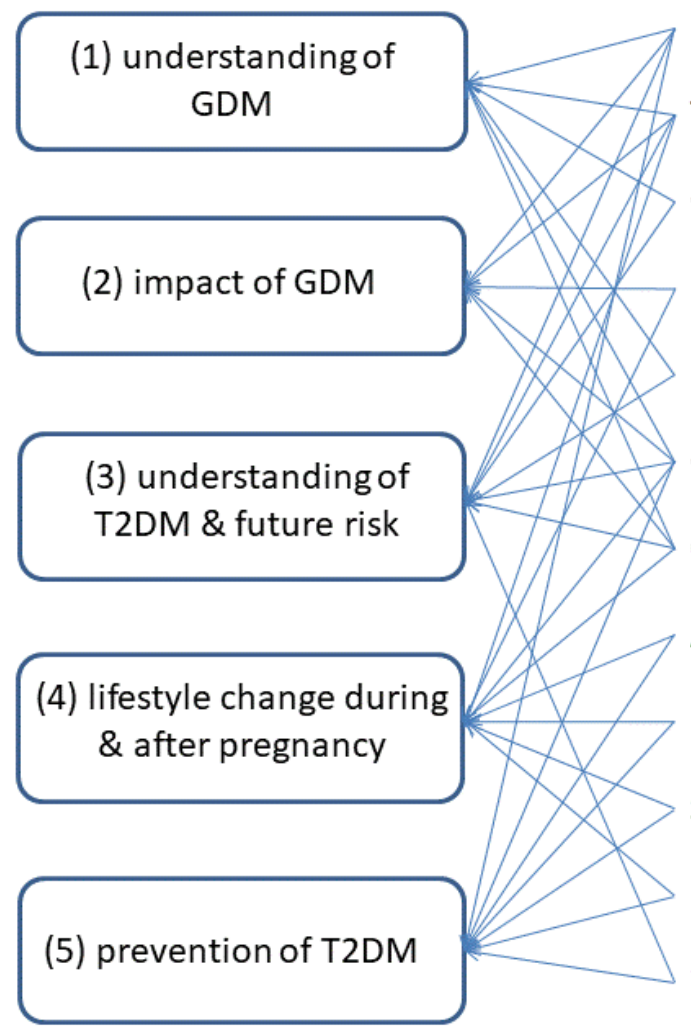

\section{Theoretical concepts}

Identity (SRM)

Timeline (SRM)

Cause (SRM)

Emotional Representations (SRM)

Illness Coherence (SRM)

Control (SRM)

Consequences (SRM)

Attitude (TPB)

Behaviour (TPB)

Subjective Norm (TPB)

Perceived Behavioural Control (TPB)

Intention (TPB) 
Appendix 1 - Illustrative excerpt from an analytical framework matrix for gestational diabetes mellitus (GDM) topic theme

\begin{tabular}{|c|c|c|c|c|c|c|c|c|c|}
\hline 2. GDM & 2.1 Identity & 2.2 Timeline & 2.3 Cause & 2.4 Emotional Representations & 2.5 Consequences & 2.6 Control & 2.7 IIIness Coherenc & 2.8 GDM Education & Theme Summary \\
\hline $\begin{array}{l}\text { P1 } \\
\text { Age: } \\
\text { late } \\
30 \text { s } \\
\text { Baby } \\
\text { age: } 3 \\
\text { months } \\
\text { Parity: } \\
\text { +2 } \\
\text { Dep: } \\
\text { Middle } \\
\text { (3) }\end{array}$ & $\begin{array}{l}\text { Felt very } \\
\text { tired but } \\
\text { questioned } \\
\text { whether } \\
\text { the high BG } \\
\text { readings } \\
\text { were down } \\
\text { to eating a } \\
\text { lot. } \\
\text { "maybe I } \\
\text { didnae } \\
\text { have it all, } \\
\text { and it was } \\
\text { just...well } \\
\underline{\text { obviously I }} \\
\text { did" }\end{array}$ & $\begin{array}{l}\text { Viewed as } \\
\text { temporary. } \\
\text { "I don't } \\
\frac{\text { need to }}{\text { remember }} \\
\frac{\text { that now }}{\text { because I've }} \\
\frac{\text { had }}{\text { her...and }} \\
\text { she tested } \\
\text { fine" }\end{array}$ & 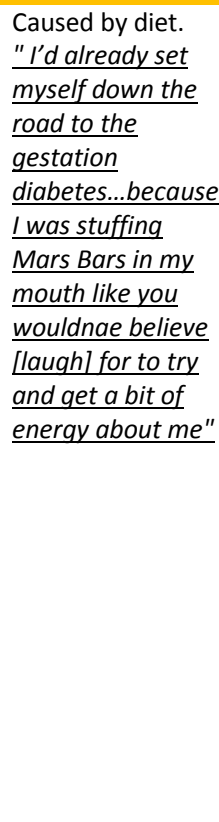 & $\begin{array}{l}\text { Saw diagnosis as a wake up call } \\
\text { but not overly concerned. } \\
\text { Mostly concerned about baby } \\
\text { rather than herself. } \\
\text { "it doesn't really matter about } \\
\text { me." }\end{array}$ & 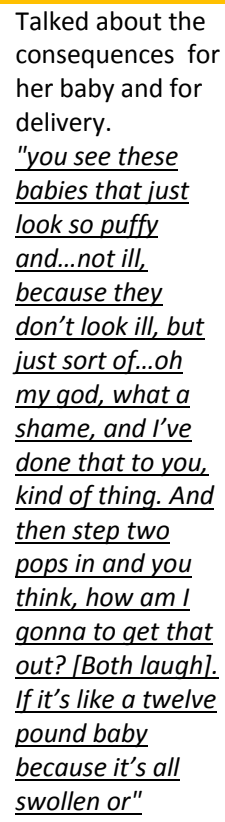 & 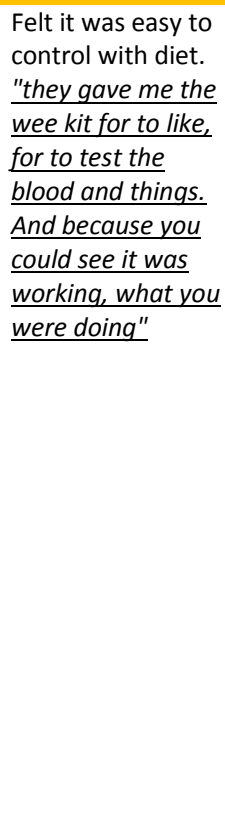 & No data & $\begin{array}{l}\text { Didn't remember much but } \\
\text { felt she it was fine at the } \\
\text { time. } \\
\text { "It was fine. It wasnae like it } \\
\text { was information overload or } \\
\text { too technical or anything } \\
\text { like that. It was alright, it } \\
\text { was alright." }\end{array}$ & $\begin{array}{l}\text { Questioned } \\
\text { diagnosis and } \\
\text { thought it was } \\
\text { caused by her } \\
\text { diet. Concerned } \\
\text { for baby rather } \\
\text { than herself. } \\
\text { Doesn't seem to } \\
\text { have had big } \\
\text { impact on her } \\
\text { life and found it } \\
\text { easy to control. } \\
\text { Viewed as } \\
\text { temporary. }\end{array}$ \\
\hline
\end{tabular}




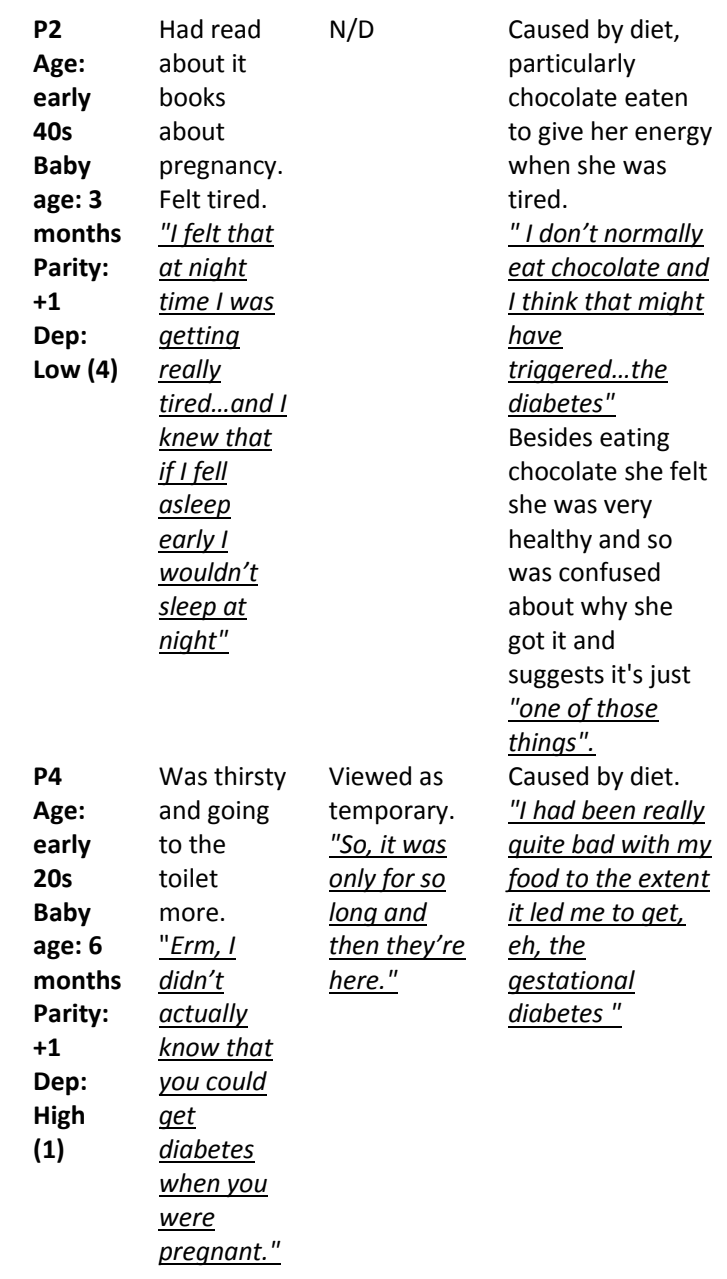

Not scared as saw it as something quite common. "it was quite common, so...that

sort of puts your mind at ease,

it didn't scare me or anything.

So, it was okay. Knowing that

lots of people get it and it was

quite normal, and the people

at the hospital were really

nice... and they spoke you

through everything that

happens... and it was fine."

Wasn't too bothered but

partner was worried and

upset.

"Erm, and...but it didn't really

bother me because my wee

sister's got diabetes and so has

my partner."

"My partner was quite,

erm...he was quite upset"
Mentioned the

risk of getting

GDM again in

future.

Found it easy to

get under contro

through diet,

particularly cutting

out chocolate.

"it was quite easy

to get under

control...it really

was, just, as I said,

cutting out the

chocolate at night"

Didn't discus apart from saying partner worried

about the chance

of the baby

having diabetes.

"he was saving he

didn't want him

to have diabetes

born and thing

like that"
Bloods were pretty normal through watching her diet. "I think, that was probably why my blood was always a lot better. Eh, and why it was never over just because had changed from just eating sweeties and crisps and

basically whatever I wanted to being a bit healthier in $m y$ diet again"
No data

Staff at hospital wer nice and didn't make too big a thing about it. Felt she already

knew a lot of what they were telling her about diet.

"and then at the hospital they were really, really

nice... and they didn't make it a big

thing... which you

don't need when

you're pregnant.

Wasn't something she knew about before pregnancy.

"Erm, I didn't actually

know that you could

get diabetes when you

were pregnant. Eh, I

didn't know that was a

thing, erm, but it was

\section{fine"}

Felt it was explained well and wasn't too complicated.
Thought it was caused by diet. Found it easy to control and saw

it as some so wasn't concerned.
Thought it was caused by he diet. Not

worried and

managed to

control through

diet. Viewed as temporary. 
